\title{
Accurate water levels using PREMO: Tool for reduction of hydrographic measurements
}

Micheline HOUNJET ${ }^{1}$, Arnout BIJLSMA ${ }^{1}$, Martin VERLAAN ${ }^{1}$, Leendert DORST ${ }^{2}$, Netherlands

${ }^{1}$ Deltares, ${ }^{2}$ Hydrographic Service of the Royal Netherlands Navy

Topic J: accurate hydrodynamics

\section{INTRODUCTION}

The Hydrographic Service of the Royal Netherlands Navy (RNLN) publishes nautical charts for the Dutch sector of the North Sea. A major source of error in the charted depths based on echo soundings is the so-called "tidal reduction" of the measurements to their Chart Datum (the vertical reference surface). Tidal reduction is the correction for the local water level, depending on tides and meteorological conditions, relative to a specified reference surface. At sea, the accurate determination of vertical position, and thereby the reduction, with respect to Chart Datum from satellite positioning is still under development. Therefore, the water levels in the survey areas are obtained from temporary tide gauges placed on the seabed or by some form of spatial interpolation between permanent tidal stations. PREMO (PREdiction Module) version 2 estimated the water levels in the survey area using a database of tidal constants to predict the astronomical tide, and water level measurements in permanent tidal stations to determine the surge heights via a sophisticated interpolation method (Delft Hydraulics, 1998). The main reason to start the development of a new tidal reduction package was the seriously reduced working area of PREMO v2, since the water level measurement in some tidal stations was not continued, and new stations were difficult to include. The implication was that (pressure) tide gauges needed to be deployed at a much larger scale again.

The availability of hydrodynamic models predicting the daily movement of the North Sea sparked the redesign of the reduction tool PREMO. The new version uses data-assimilated model predictions of water levels, astronomical tides and surges stored in the databases of Rijkswaterstaat, Ministry of Infrastructure and the Environment (RWS). PREMO enables hydrographic vessels like the HNLMS Snellius and the HNLMS Luymes of the RNLN to retrieve the water levels along their route using an internet connection to access the databases. However, when preferred, reduction work by PREMO may well be performed by shore staff (RWS). Application by third parties is also anticipated.

The new development is a cooperation of the Netherlands Hydrographic Institute (NHI) partners, the Hydrographic Service of the RNLN and RWS, with research institute Deltares. Deltares is the developer of the new tidal reduction package, the Hydrographic Service of the RNLN and the North Sea Department of RWS are the end users. The RWS Centre for Data and ICT (DID) and RWS Centre for Water Management (WD) provide support on operational measurements and modeling and database services.

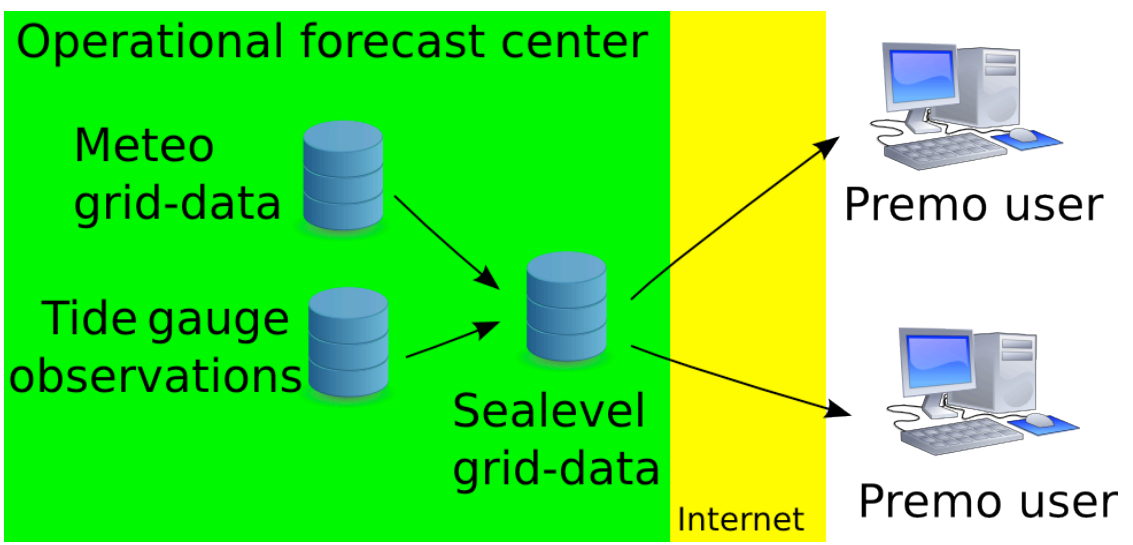

Figure 1: Data flow from operational forecast center via the internet to the PREMO users. 


\section{NEW METHOD OF TIDAL REDUCTION}

The new PREMO version 3 is based on the open source Delft-FEWS software, see Gijsbers et al. (2008) and http://oss.deltares.nl/. This software was originally developed for water level and discharge forecasts in rivers, but is now used for all kinds of operational systems. For the development of PREMO it means that much standard functionality of FEWS can be used. PREMO is designed as a standalone system, meaning that no external server is used to carry out tasks or model computations. An internet connection to the external MATROOS database of RWS is essential for PREMO, however. Data presented by the user or from MATROOS are imported in a local data store. The data in the local data store can be presented or manipulated in various ways by a graphical user interface.

The water levels required for the reduction are based on the computations four times per day of the Hydro Meteo Centre (HMC) of RWS North Sea. The HMC North Sea exports the computational results to the MATROOS database of RWS, where they become available for use by PREMO, see Figure 1. This means that the tidal reduction by PREMO can be repeated later, as long as the data is available in MATROOS.

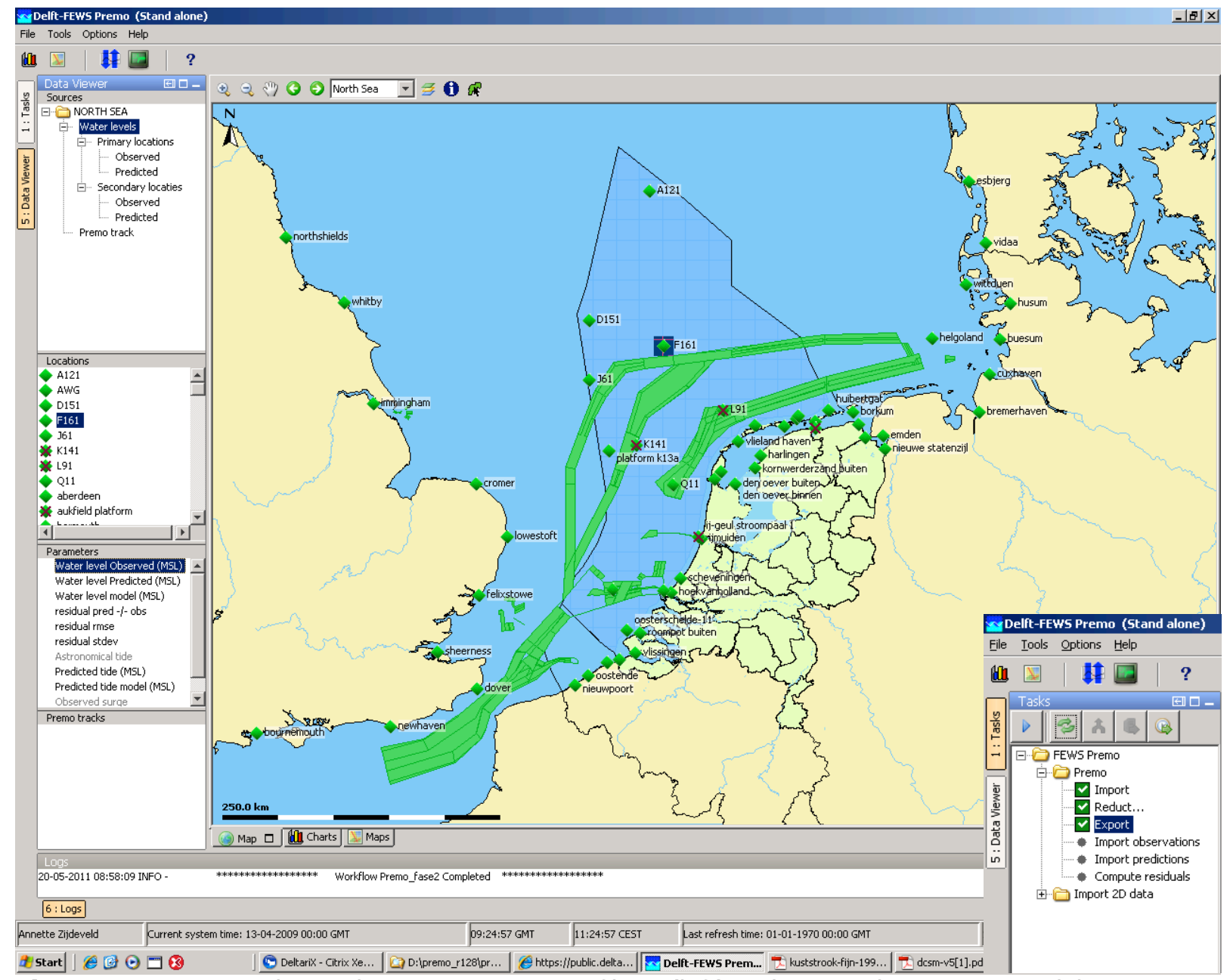

Figure 2: PREMO Explorer, showing Data Viewer filters (left) and Map with permanent tidal stations, with warning symbols for missing data and reduction errors, depending on the sources, locations and parameters selected. Inset: contents of PREMO Tasks tab (right).

In PREMO the user can choose between two hydrodynamic models from which results are available in MATROOS: the Dutch Continental Shelf Model (DCSM) version 5 (see e.g. Gerritsen et al. 1995) and a 
more refined model of the coastal zone. The DCSM covers the entire NW European Continental Shelf with a resolution of about $8 \mathrm{~km}$ and is driven by tidal constants at the ocean boundary and wind and atmospheric pressure fields provided by Royal Netherlands Meteorological Institute KNMI. The water levels computed by DCSM v5 are not directly used for reduction. To improve the accuracy, a special tidal database was created, which is combined with surge heights computed in the operational cycle. Both tides and surges are improved further by data-assimilation. The model of the coastal zone, the Kuststrook-fijn Model v4 of RWS, covers the entire Dutch coast to about $60-70 \mathrm{~km}$ offshore. The boundary conditions are derived from DCSM via an intermediate model, and a Kalman Filter is used to further enhance the accuracy of the model results.

The operational models provide water levels relative to Mean Sea Level (MSL). For tidal reduction these levels need to be converted to Chart Datum, which is defined as Lowest Astronomical Tide (LAT), see Kwanten and Elema (2007). The definition of LAT with respect to MSL is available on a grid, and this information is included in the MATROOS database where, it can be approached by PREMO.

The graphical user interface of PREMO Explorer helps to perform the tidal reduction. The Explorer, see Figure 2, shows the various components, like the Tasks Tab, the Log window and the Data Viewer. The latter includes Maps, Charts and Filter options, which can be used to inspect and document the reduction results.

\section{RESULTS}

Both during the development and in the Acceptance Phase, the North Sea Department of RWS and the Hydrographic Service of the RNLN tested the performance of PREMO v3 by comparison with measurement series of pressure tide gauges. These reference measurements have been selected from surveys carried out in a period of several years $(2009-2011)$ and spread over the Dutch sector of the Continental Shelf. Figure 3 shows a representative result of such an accuracy analysis. For the tide gauge series GM3 at position $53^{\circ} 43^{\prime} 06.0^{\prime \prime} \mathrm{N} 3^{\circ} 06^{\prime} 06.0^{\prime \prime} \mathrm{E}$, about $140 \mathrm{~km}$ NW of Den Helder, the standard deviation of the difference between measured water levels and PREMO is $0.057 \mathrm{~m}$. This is well within the required accuracy.

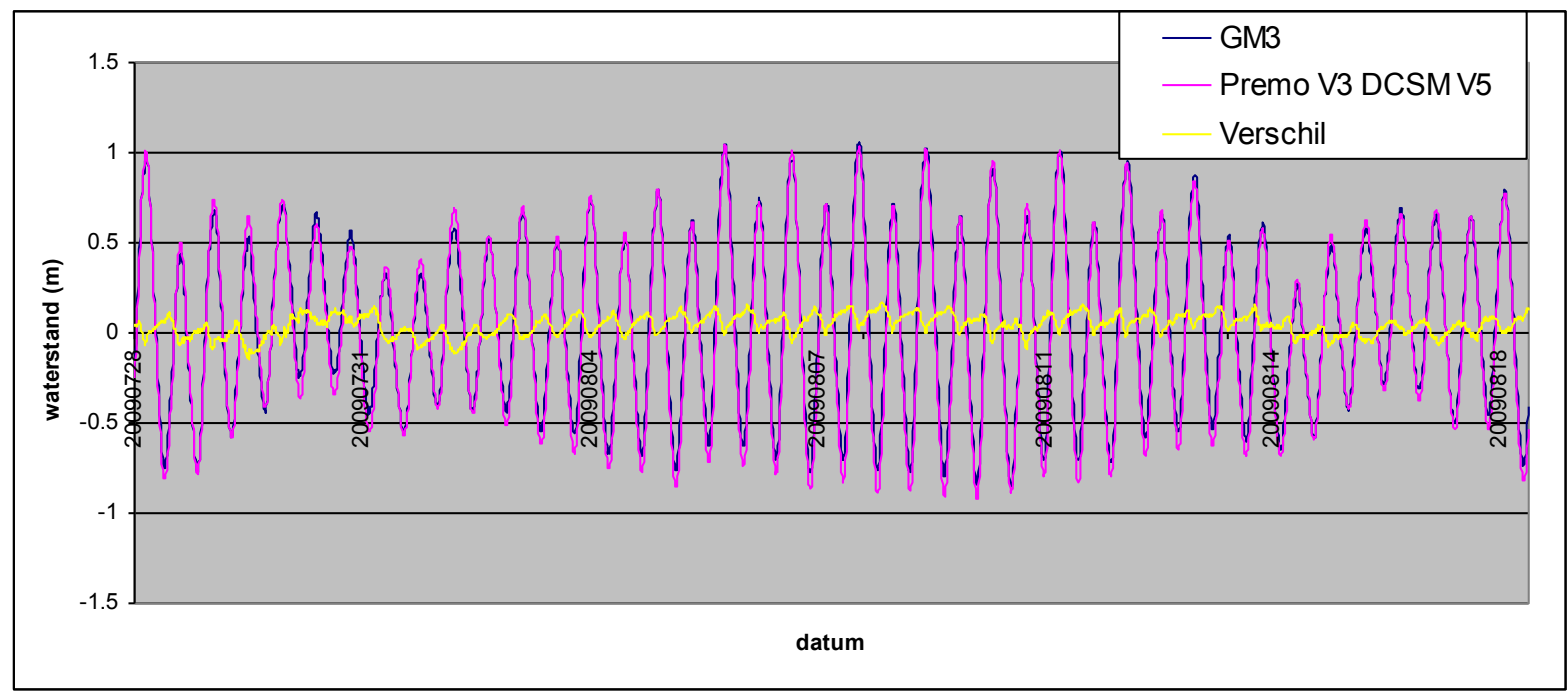

Figure 3: Accuracy analysis for bottom tide gauge at position $53^{\circ} 43^{\prime} 06.0^{\prime \prime} \mathrm{N} 3^{\circ} 06^{\prime} 06.0^{\prime \prime} \mathrm{E}$. PREMO v3 (pink line) against the water level measurement GM3 (blue line), and their difference (yellow line).

The assessment of the measurements spread over the Dutch sector of the Continental Shelf generally showed good results. Based on the difference between PREMO and measurements, in most cases the $95 \%$ accuracy intervals were about $+/-0.1 \mathrm{~m}$. An exception was found at the Dutch coast near 
Petten, with a $95 \%$ accuracy interval of $+/-0.24 \mathrm{~m}$. Due to the specific characteristics of the local tides, the numerical models may have some difficulty to accurately reproduce the water levels here. This needs to be investigated further.

The application of PREMO in an actual survey situation is illustrated by Figure 4. For the survey track imported in PREMO (Figure 4, left panel), the tidal reduction is computed, depending on the selected database and reference surface (LAT). The user can inspect the reduction result in various ways, e.g. in a time-plot along the survey track (Figure 4, right panel). Additionally, the user can verify and document the quality of the tidal reduction during the survey period in all stations of the tide gauge monitoring network.

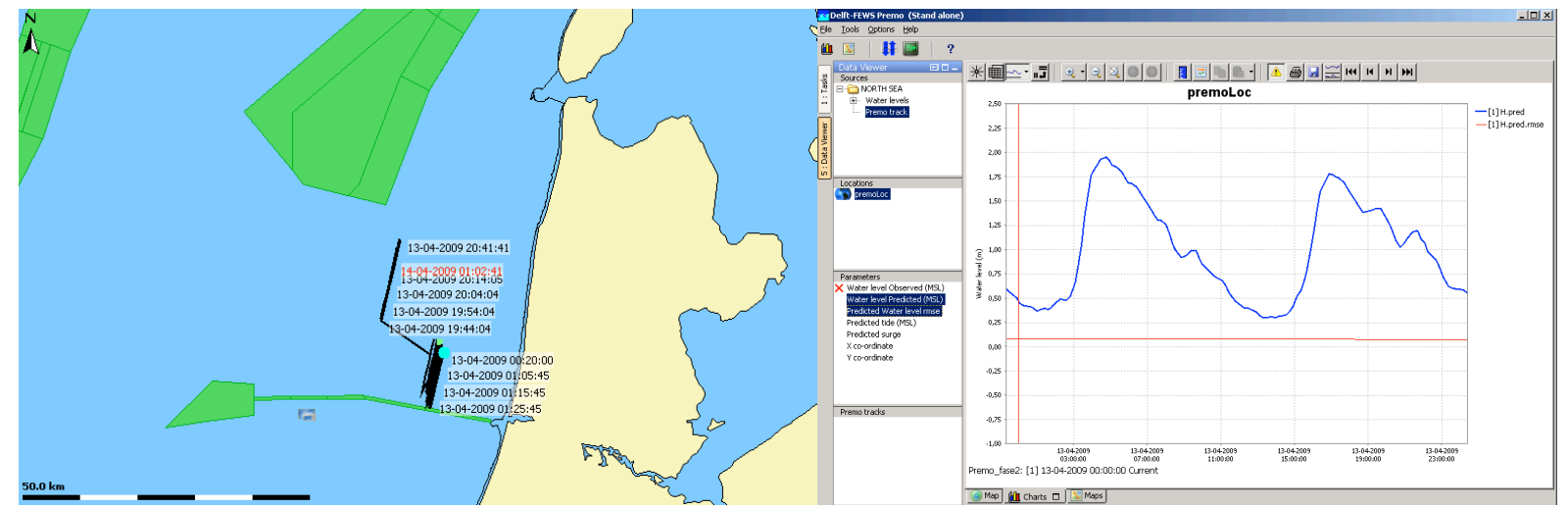

Figure 4: Survey track presented in PREMO v3 (left) and the computed tidal reduction along the track (right).

\section{DISCUSSION}

During the tests, PREMO v3 demonstrated that the accuracy objectives for tidal reduction are met. Furthermore, it proved to work well on board of the hydrographic survey vessels of the RNLN. Other advantages compared to previous versions are the realization of a consistent reduction tool for all NHI partners, with greater operational flexibility, less dependent on the availability of individual measurement stations, and real-time reduction in survey track position. Compared to pressure tide gauges PREMO provides an unambiguous reference level for the water levels, and a more efficient and reliable reduction procedure. Time and risks related to instrument deployment and recovery are avoided, as are data and accuracy loss due to movement or settling of tide gauges on the seabed.

The main advantage of the model-based approach is that with every model update the user benefits directly from increased accuracy. By 2013, the inclusion of a new hydrodynamic model (Zijl et al., 2009 ) in the operational system of RWS will make the PREMO results even more accurate. The increased accuracy will allow the multibeam echo sounding tracks to be spaced further apart, saving time and money while still meeting the accuracy requirements.

The PREMO concept potentially has a much wider field of application, e.g. for other measurements requiring tidal reduction, or dredging operations and surveying in the North Sea. It can also be applied in other sea areas, if operational models and measurements are available. However, today, data on various hydrodynamic parameters are generally available over large sea areas, but these data are buried in databases. The techniques used in PREMO can make this information available for a large group of users for whom vertical positioning, currents, wave conditions, or meteorological parameters are important, for example for offshore and shipping activities. This approach can help to optimize cost and reduce risks.

\section{CONCLUSION}


The new FEWS based PREMO version 3 provides an easy to use tool for tidal reduction. Its strength is the generic open source software platform of Delft-FEWS, which makes efficient use of existing databases of operational water level measurements, model predictions and hindcasts of other organizations. An important advantage of this approach is that users directly benefit from increased accuracy for tidal reduction, introduced by updates of the operational models.

PREMO proved to function well both on board of the hydrographic survey vessels and ashore, providing an accurate tidal reduction in agreement with RNLN and RWS requirements. Besides tidal reduction of bathymetric surveys, the FEWS-PREMO concept essentially has an even wider range of potential application: tidal reduction of other surveys in the North Sea, and elsewhere in the world, provided that operational models and measurements are available. The concept can also easily be extended to currents, waves, and meteorological parameters.

\section{REFERENCES}

Delft Hydraulics. 1998. Manual PREMO-offline version 2.0 - Offline generation of water levels for offshore tidal reduction.

Gerritsen, H., H. de Vries, and M. Philippart. 1995. "The Dutch Continental Shelf Model." In Quantitative Skill Assessment for Coastal Ocean Models, Coastal Estuarine Stud., Vol. 47, edited by Lynch, D. R. and Davies, A. M., 425-467, AGU, Washington, D. C. doi:10.1029/CE047p0425.

Gijsbers, P.J.A., M.G.F. Werner \& J. Schellekens. 2008. "Delft FEWS: A proven infrastructure to bring data, sensors and models together." International Congress on Environmental Modelling and Software. International Environmental Modelling and Software Society (iEMSs).

Kwanten, M.C. and Elema, I. 2007. "Converting NL Chart Datum: Consequences of Change from MLLWS to LAT." Hydro International, Volume 11, number 4, April.

Zijl, F., R. Plieger, D.K. Vatvani, M. Verlaan, H. Gerritsen, \& D. Twigt. 2009. DCSM v6 model setup and calibration of tidal propagation. Delft, Deltares report.

\section{BIOGRAPHIES}

Micheline HOUNJET is a Senior Advisor at Deltares' Hydrodynamics and Real-time Systems department in the Marine and Coastal Systems unit. She works on tool-development and serious gaming techniques for marine and coastal application.

Arnout BIJLSMA is a Senior Researcher and Advisor Hydrodynamics at Deltares. He is specialized in tide, wind and density driven flow phenomena in harbours, estuaries, coastal seas and shelf seas, and has a long-term experience with tidal analysis and prediction and tidal reduction.

Martin VERLAAN is Senior Researcher Oceanography/Mathematics at Deltares and Assistant Professor at the Mathematics department of the Delft University of Technology. He works in the field of data assimilation \& operational forecasting, and is actively involved in the development of OpenDA, a generic software package for data-assimilation.

Leendert DORST is head of the Department of Geodesy and Tides of the Hydrographic Service, Royal Netherlands Navy, where he works on technical aspects of the law of the sea, advice on maritime positioning, statistical aspects of bathymetric surveying, and transformations between coordinate systems. He is a member of the Subcommittee on Marine Geodesy of the Netherlands Geodetic Committee, and of the Working Groups on Standards for Hydrographic Surveys and on Data Quality of the International Hydrographic Organization. 
CONTACT DETAILS (of corresponding author only)

Micheline HOUNJET

Deltares

Rotterdamseweg 185

Delft

THE NETHERLANDS

Tel.: +31622546111

Fax: +31883358582

Email: micheline.hounjet@deltares.nl

Web site: www.deltares.nl

LinkedIn account: yes

Facebook account: no

Twitter account: yes 